\title{
Wuevos horizontes en el tratamiento de algunas enfermedades oculares
}

\author{
New horizons in the treatment of some eye diseases
}

José Antonio Roca-Fernández ${ }^{1}$, Daniela Roca-Contreras ${ }^{2}$

\section{Resumen}

En los últimos años la oftalmología ha progresado significativamente gracias a la tecnología. En el tratamiento de la distrofia corneal de Fuchs era necesario realizar trasplante de córnea, en la actualidad existe una nueva modalidad de tratamiento llamada descemetorrexis, la cual tiene una muy alta tasa de éxito y no requiere de trasplante. En cuanto a cirugía de la catarata y el implante de lentes intraoculares, éstos han progresado asombrosamente, pudiendo lograr en la actualidad visiones prácticamente perfectas luego de la cirugía. En cuanto al tratamiento de algunas enfermedades hereditarias de la retina, las cuales eran hasta hace muy poco intratables, contamos en la actualidad con la terapia génica que puede detener e incluso revertir la pérdida de visión.

Palabras clave: $\quad$ asplante de córnea, distrofia de Fuchs, catarata, lente intraocular, distrofia de retina, terapia génica.

\section{Abstract}

In recent years ophthalmology has made significant progress thanks to technology. Corneal transplantation was needed to treat Fuchs' dystrophy, today there is a new treatment modality called descemetorhexis, which has a very high success rate and does not require transplantation. As regard to cataract surgery and the implantation of intraocular lenses, the lenses have progressed amazingly, and can currently achieve almost perfect vision after surgery. With regard to the treatment of some inherited retinal diseases, which were until recently intractable, we have today gene therapy that can stop and inclusive reverse vision loss.

Keywords: Corneal transplantation, Fuchs'dystrophy, cataract, IOL, retinal dystrophy, gene therapy.

\section{Introducción}

Los avances más recientes en recursos disponibles para el diagnóstico y el tratamiento de afecciones oculares que, lamentablemente, se encuentran disponibles solo en centros altamente especializados en las grandes ciudades del Perú son muchos y dentro de los que están los nuevos exámenes de tomografía de coherencia óptica (OCT) de todos los segmentos del ojo, que son de gran ayuda para un mejor diagnóstico, la facoemulsificación y laser de fentosegundo para la cirugía de catarata, las mejoras en vitrectomía, el uso de varios tipos láser para cirugía refractiva, Glaucoma y especialmente en afecciones de la retina de diversa índole.

Así mismo, los nuevos medicamentos como la terapia con supresores del factor endotelial vascular (terapia antiVEGF) que tienen acción anti-angiogénica para tratar la retinopatía diabética, las degeneraciones de la retina de las personas de la tercera edad y otras.
A ello debe agregarse lo que se ha logrado en biología molecular y genética ${ }^{(1)}$ que está cambiando la atención en los grandes centros oftalmológicos del mundo para las enfermedades genéticamente determinadas y la predisposición de adquirir otras de esta índole.

En esta oportunidad nos ocuparemos de los avances en el tratamiento de patologías de la córnea, avances en lentes intraoculares y el tratamiento de algunas patologías retinianas que son muy novedosas y que se usan excepcionalmente.

\section{Avances en el Tratamiento de Patologías de Cornea}

Con respecto al tratamiento de algunos problemas de transparencia de la córnea, hace algunos años vimos que para algunas distrofias corneales no era necesario realizar un trasplante total de córnea ${ }^{(2)}$ (queratoplastia penetrante), si no

${ }^{1}$ Profesor Asociado Universidad Peruana Cayetano Heredia, profesor auxiliar Universidad Nacional Federico Villarreal, Expresidente Sociedad Peruana Oftalmología, Expresidente Sociedad Panamericana Retina y Vitreo, Fellow de Retina y Vitreo Universidad de Chile, y en Jules Stein Eye Institute, University of California Los Angeles, UCLA. ${ }^{2}$ Residente de tercer año, Fundación Oftalmológica Nacional, Bogotá, Colombia. Universidad del Rosario. 
que realizando procedimientos parciales (queratoplastia lamelar), tanto el pronóstico como el manejo post operatorio eran mejor; no obstante, a pesar de las ventajas de los procedimientos lamelares para estas patologías, en algunos países como el nuestro, el conseguir el botón donante continúa siendo un problema.

En la actualidad para la distrofia de Fuchs y otras similares, se está realizando Descemetorrexis sin trasplante como intervención primaria, con el uso de inhibidores ROCK (Rho-associated kinase), principalmente el ripasudil, como agente de salvación en casos no exitosos. Hasta hace algunos años estaba prácticamente proscrito el dañar o tocar el endotelio corneal debido a que esto condicionaba opacidad y edema de la córnea. En la actualidad existe esta nueva forma de tratamiento, que consiste en realizar una descemetorrexis central de no más de $4 \mathrm{~mm}$ de diámetro, sin trasplante, obteniendo un éxito quirúrgico (cornea transparente) en al menos $75 \%$ de casos. En los casos en los cuales la córnea permanece opaca luego de dos meses de realizado el procedimiento quirúrgico, se utiliza el tratamiento tópico con gotas que contienen inhibidores ROCK, obteniendo la transparencia corneal en la mayoría de ellos.

\section{Avances en Lentes Intraoculares}

En cuanto a innovación en lentes intraoculares existen algunas novedades que van a cambiar pronto nuestra aproximación quirúrgica ${ }^{(3)}$. Contamos con dos lentes intraoculares de tipo "modular", el lente Harmini Modular IOL (ClarVista Medical) y el Precisight (InfiniteVision Optics) ${ }^{(4)}$, estos lentes tienen una base con las hápticas que se implanta dentro del saco capsular, y la óptica del lente puede cambiarse con facilidad si es que fuera necesario, si tenemos una sorpresa refractiva o si el paciente no se adapta a la multifocalidad. El lente intraocular de la compañía RxSight llamado RxLAL (Light Adjustable Lens), aprobado por la FDA, es un lente al cual se le puede modificar el poder luego de implantado, hasta 2.00 dioptrías de esfera y 2.00 dioptrías de astigmatismo. Según la FDA, los pacientes con este tipo de implante tienen dos veces más posibilidad de tener visión 20/20 sin utilizar ningún tipo de correctores que aquellos pacientes operados con lentes intraoculares usuales.

También existe otro lente intraocular creado por Perfect Lens, este es un lente hidrofóbico que a través de una tecnología llamada "phase wrapping" traducido como "envoltura de fase", utilizando un láser de femtosegundo ${ }^{(5)}$, se talla un lente en el lente implantado utilizando ópticas tipo fresnel; el láser cambia la hidrofilicidad del lente de acrílico cambiando su índice refractivo. Este tipo de tecnología puede ser utilizado con cualquier tipo de lente intraocular que sea de acrílico hidrofóbico, y puede cambiar el poder del lente hasta 3.00 dioptrías, pudiendo corregir esferas y cilindros, además, puede convertir un lente monofocal en uno multifocal o revertir un lente multifocal implantado en uno monofocal.

\section{Avances en el Tratamiento de Patologías Retinianas}

Algunas de las patologías retinianas más comunes, tales como la degeneración macular asociada a la edad (DMAE), las distrofias retinianas y la retinopatía diabética tienen una etiología compleja, son influenciadas por factores genéticos y ambientales, y requieren tratamientos continuos, crónicos, con pobres resultados finales. Estas patologías tienen un elevado impacto social y económico, debido a que el paciente depende de otras personas para realizar sus actividades diarias y como tratamiento debe recibir inyecciones intravítreas de anti-factor de crecimiento del endotelio vascular (anti-VEGF) o esteroides intravítreos con dispositivos de liberación lenta (ej. Ozurdex®, Retisert $(\mathbb{B})$ en forma continua y reiterativa. Los pacientes deben ser monitorizados para evaluar las posibles complicaciones de estas inyecciones (aumento de la presión intraocular, hemorragia vítrea, desgarros de retina, etc.). En los últimos años la terapia génica es una opción terapéutica importante ${ }^{(6)}$, ofreciendo sistemas virales y no virales capaces de provocar la expresión del factor terapéutico por las propias células de la retina por períodos de tiempo muy prolongados. Se introduce un vector (viral o no viral) que libera una secuencia exógena de DNA llamada transgen, que cuando esta secuencia se introduce dentro de la célula blanco producen unas proteínas que "reparan" el código genético de la célula dañada. Los vectores virales son preferidos a los no virales, por tener efectos a largo plazo y ser más eficientes. Los virus más utilizados para el tratamiento génico son los adenovirus, los cuales se modifican para que no sean patogénicos ni replicativos, pero que sí puedan transportar el material génico, infectando las células que queremos "tratar", liberando en ellas el material génico que produce transducción celular y haciendo que estas células se reparen. En la actualmente podemos reemplazar un gen mutado por uno sano, podemos silenciar un gen con función anormal para evitar su expresión, podemos adicionar y/o eliminar genes que están indirectamente relacionados con la fisiopatología de la enfermedad y corregir genéticamente la secuencia del gen mutado. La liberación de genes en el ojo se puede llevar a cabo mediante la inyección de los vectores por diferentes vías (principalmente intravítreo y sub-retiniano); el criterio para la elección del lugar de inyección depende de las características del vector y de qué célula o tejido deseemos tratar; si queremos tratar la retina externa inyectaremos el vector en el espacio subretiniano, si queremos tratar la retina interna inyectaremos el vector en la cavidad vítrea. La inyección del vector en el espacio subretiniano permite "transducir" el epitelio pigmentado de la retina (EPR) y la capa de fotoreceptores; es decir, es el lugar adecuado para inyectar el vector en el tratamiento de las diferentes distrofias retinianas, tanto del EPR como de la retina misma (amaurosis congénita de Leber, enfermedad de Stargardt, acromatopsia, y retinosis pigmentaria). La inyección intravítrea del vector permite la transducción en las capas internas de la retina, principalmente células ganglionares y células de Müller, lo cual sería de utilidad en el manejo de la apoptosis ganglionar que se presenta en el glaucoma crónico y en el tratamiento de las telangiectasias tipo $\mathrm{MacTel}^{(7)}$, enfermedad neurodegenerativa de las células de Müller. 
El ojo es un lugar privilegiado para la terapia génica ${ }^{(7)}$, debido a que es pequeño, se encuentra aislado del resto del organismo por una cubierta (la esclera) y por la barrera hematoretiniana, y además está compartimentado; estas características permiten la introducción de los diferentes vectores al espacio subretiniano o a la cavidad vítrea con mínima difusión extraocular, lo cual provoca mínima respuesta inmune $^{(8)}$.

Hace poco más de un año, en el Bascom Palmer Eye Institute, la Dra. Audina Berrocal, operó a un niño que padecía de Amaurosis Congénita de Leber, inyectándole en el espacio subretiniano Voretigene neparvovec (Luxturna ${ }^{\circledR}$ ), el primer tratamiento génico oftalmológico comercialmente disponible, mejorando sustancialmente la visión y la calidad de vida del paciente; cabe mencionar que este tratamiento es definitivo, y no es necesario repetirlo.

Para concluir reiteramos que en nuestro país la nueva tecnología en oftalmología no llega a toda la población por razones obvias pero se están haciendo esfuerzos para mejorar la atención a la comunidad con los pocos recursos que contamos, siendo necesario instaurar una política preventiva a fin de evitar las enfermedades oculares prevalentes y la ceguera.

\section{Referencias bibliogrfaficas}

1. Liu MM, Tao J, Chan C. Gene therapy for ocular diseases. Br J Ophthalmol. 2011;95:604-12.

2. Moloney G, Petsoglou C, Ball M, et al. Cornea 2017;36:64248.

3. Sahler R, Bille JF, Enright S, Chhoeung S, Chan K. Creation of a refractive lens within an existing intraocular lens using a femtosecond laser. J Cataract Refract Surg 2016;42(8):1207-15.

4. Wörtz G. Making room for future IOL technologies. Cataract and Refractive Surgery Today, June 2019.

5. Bille JF, Engelhardt J, Volpp HR, et al. Chemical basis for alterations of an intraocular lens using a femtosecond laser.
Biomed Opt Express 2017;8(3):1390-1404.

6.Stein L, Roy K, Kaushal S. Clinical gene therapy for the treatment of RPE65-associated Leber congenital amaurosis. Expert Opin Biol Ther. 2011;11:429-39.

7. Chacon-Camacho OF, Astorga-Carballo A, Zenteno JC. Terapia génica para enfermedades hereditarias oftalmológicas: avances y perspectivas. Gac Med Mex 2015;151:501-11.

8. Strachan T, Read A. Genetic approaches to treating diseases. In Human Molecular Genetics. Strachan T, Read A (Eds). Garland Science. 4a. ed. New York; 2011;677-704.

Citar como: Roca-Fernández JA. Roca-Contreras D. Nuevos horizontes en el tratamiento de algunas enfermedades oculares. Diagnóstico(Lima).2019;58(2):91-3. DOI: https://doi.org/10.33734/diagnostico.v58i2.211

Correspondencia: José Antonio Roca-Fernández Correo electrónico: jaroca62@yahoo.com

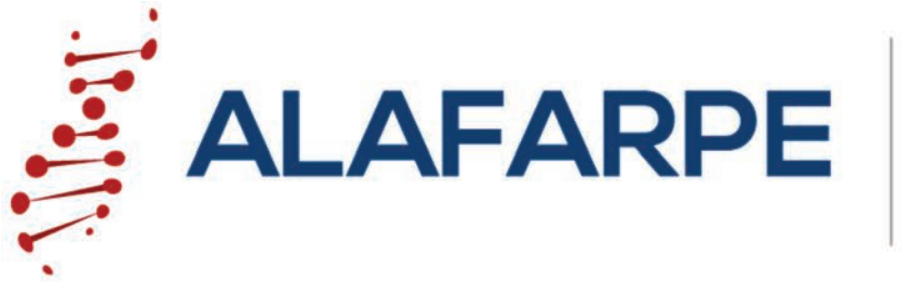

\title{
ASOCIACIÓN NACIONALDE LABORATORIOS FARMACÉUTICOS
}

\section{CORREO ELECTRÓNICO: \\ alafarpe@alafarpe.org.pe}

\author{
WEB: \\ www.alafarpe.org.pe
}

